\title{
Combining Constructivism with Practicality to Promote College English Teaching
}

\author{
Huang Rong \\ Wuhan Huaxia University of Technology, Wuhan Hubei P.R.430223, China
}

Keywords: Constructivism; preparation; learning; communication; explanation; review

Abstract: College English teaching is mostly based on teachers, ignoring the concept that students are the main body of language learning and weakening the enthusiasm of students. The purpose of this paper is to apply the concept of constructivism to teaching, emphasizing the subjective meaning of students, with a view to improving students' ability to learn language.

\section{Introduction}

Construction was developed from the cognitive learning concept proposed by the famous Swiss psychologist Piaget. The studies of O.Kemberg and R.J. Stemberg have enriched and perfected the theory of Construction. Constructivist advocacy should be conducted under the guidance of teachers and centered on learners. It not only emphasizes the cognitive subject role of the learner, but also ignores the teacher's guiding role and regards the teacher as the helper and facilitator of meaning construction, rather than the instructor and indoctrinator of knowledge ${ }^{[1]}$.

\section{Constructivist model}

\subsection{Preview}

"Teachers need to prepare lessons for lectures and students must prepare for classes. This is the preparation. The main tasks are to review and consolidate old knowledge, to initially perceive new textbooks and to prepare for new knowledge." In daily learning, students often prepare It is equivalent to reading the text. In fact, this is only a step in the preview. By combining construction theory, we believe that the preparation should be divided into three steps: reading, reviewing, recording and thinking. For questions, they should always consult the reference books; for difficult questions, they should also take the initiative and record in time. In addition, a higher level of preparation for the preparation is thinking. "Require students to think according to the tips, texts and exercises. If the content of the tips is true, the summary of the topic, the division of the levels, the understanding of the sentences and the analysis of the writing characteristics can be solved." Only the preparations are sufficient. In order to be fully prepared for the class ${ }^{[2]}$. The constructivist teaching curriculum model is shown in Figure 1. 


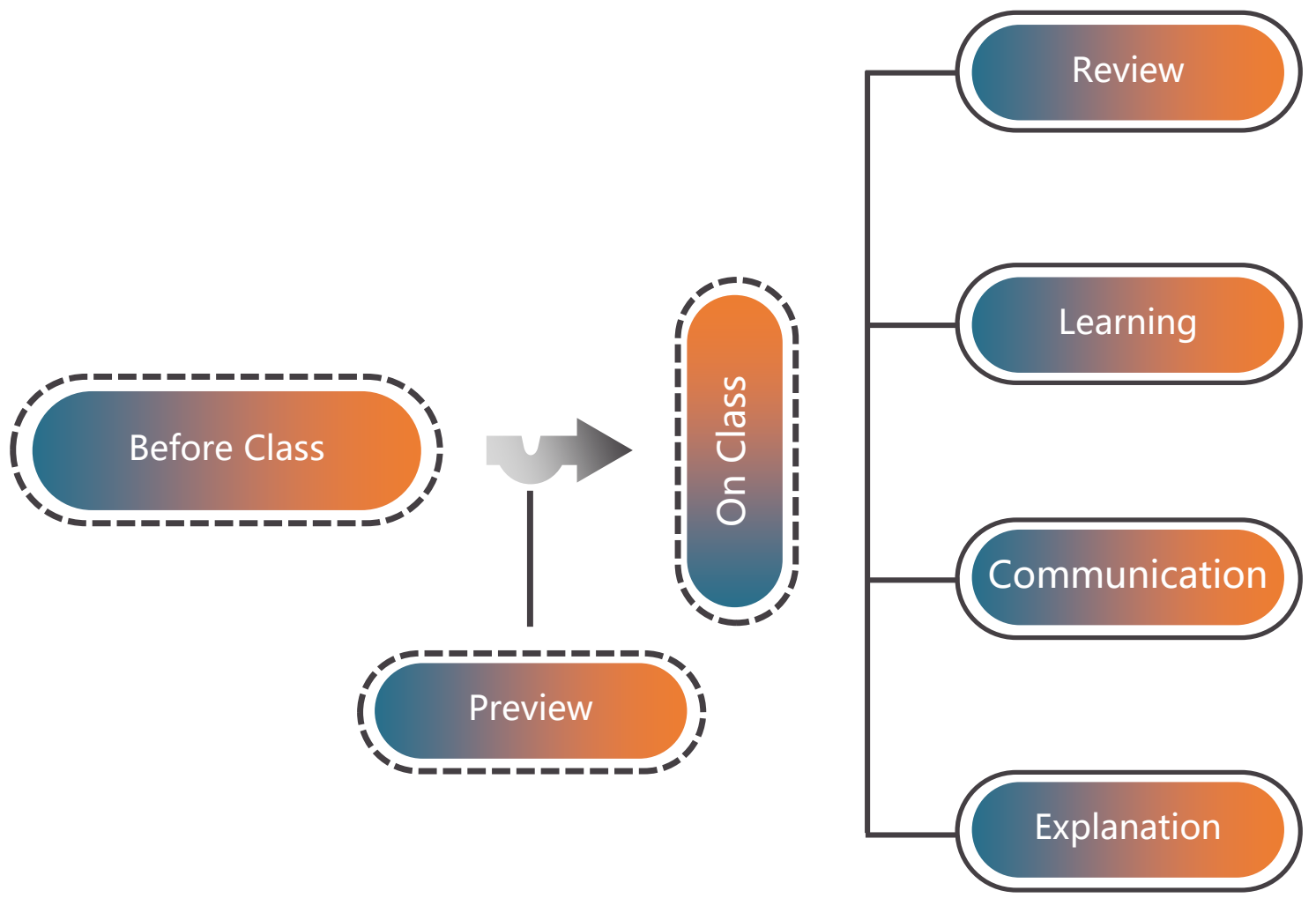

Figure 1 Constructivist teaching curriculum model

\subsection{Learning}

"Learning is a relatively long-lasting change in the behavior, ability, or tendency of an individual in a particular situation, due to practice or repeated experience." Construction believes that "learning is the process by which learners actively construct internal psychological representations, emphasizing Learning initiative in the learning process. The learning process includes: constructing the meaning of new information, using the original experience to transcend the information provided; transforming and reorganizing the original experience. Learning is both personalized and social. Activities, learning requires dialogue and cooperation. Construction emphasizes the initiative of learning."

\subsection{Communication}

The learning process is a two-way interaction process between new and old knowledge experiences, which is the process of interaction between learners and the learning environment. Construction believes that "the interaction between learners and the surrounding environment plays a key role in understanding the content of learning ${ }^{[3]}$." This requires "students to discuss and communicate together under the guidance and guidance of teachers. To jointly establish a learning group and become one of them." In the classroom, we often ask students to propose and discuss issues after the preparation and study. The teacher puts forward some more difficult questions for the problem, sets the relevant situation, guides the students to discuss, stimulates the students' expression desire, "uses the relevant experience in their original cognitive structure to assimilate and index the new knowledge that is currently being learned. Thus giving new knowledge a certain meaning" to achieve the "assimilation" process of Construction. Of course, in the discussion and exchange, students often can't solve all the problems and we need to enter the process of 
"compliance".

\subsection{Explanation}

Construction believes that "learning is not passively receiving information stimuli, but actively constructing meanings. It is based on its own empirical background and actively selects, processes and processes external information to gain its own meaning. External information itself has no meaning. The meaning is that learners construct through repeated and two-way interaction processes between new and old knowledge experiences ${ }^{[4]}$. Assimilation is the quantitative change of cognitive structure, which is the qualitative change of cognitive structure. The process of learning refers not only to the accumulation of simple information, but also to the realization of conflicts involving the experience of new and old knowledge and the process of cognitive restructuring that may arise from it. After the first three learning processes, we can carry out "compliance" with the problems that "assimilation" cannot solve. That is to say, under the teacher's explanation, by designing a new situation, the existing cognitive structure is transformed and reorganized to realize the construction of new knowledge meaning. In the traditional classroom, due to the lack of vivid and rich practical situation construction, learners often encounter difficulties in the meaning construction of knowledge.

\subsection{Review}

Construction believes that the construction of meaning is the ultimate goal of the teaching process. By helping students to reconcile the learned knowledge and complete the new meaning construction, it is to help students to deeply understand the nature and regularity of the things reflected in the current learning content and the internal relationship between the things and other things. The process of understanding. Constructivist teaching theory supports students' reflection on learning content and process, develops their self-control skills and evaluates whether to complete the meaning construction, in order to become an independent learner. Usually, we use the form of teacher design exercises to select some exercises that are consistent with the teaching content and are characteristic of the students and can mobilize subjective initiative to review and review the new knowledge construction. At the same time, teachers should also compare the learning objectives, help the deviations in the learning and enable the learners to gain a leap in understanding and understanding of things.

\section{Reflections on Construction Classroom Teaching}

College English listening and speaking teaching based on Construction theory and network multimedia technology is in line with the development trend of college English reform in the country. It also reflects the characteristics of the new teaching mode assisted by multimedia technology in the new era, which can greatly mobilize students' classrooms. Enthusiasm to improve students' learning autonomy. However, in this experiment, this teaching mode did not fully realize the author's experimental expectations. Although there is a significant improvement in improving students' initiative, improving classroom activity and cultivating students' interest in listening and speaking, the effect on test-based listening performance is not obvious. Through questionnaires, interviews and teaching for students. Reflections, the author believes that the reasons can be summarized as follows ${ }^{[5]}$. The hardware and software of the constructivist teaching curriculum model are shown in Figure 2. 


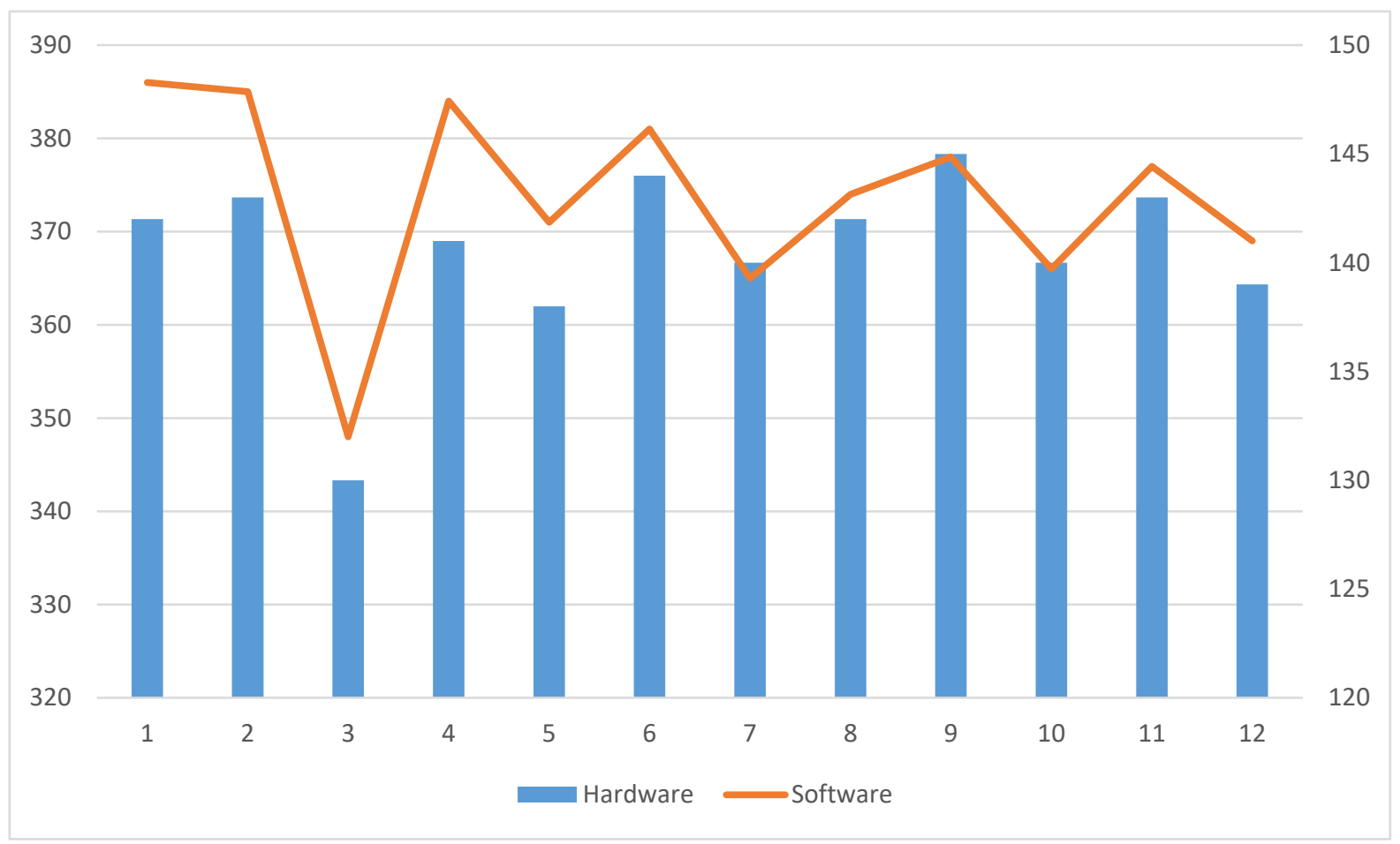

Figure 2 Hardware and software of the constructivist teaching curriculum model

\subsection{The time span of the entire experiment is not enough}

Many students receive only a small number of listening courses at the high school level. Even a small number of listening classes are almost all exam questions. Students are passive recipients of information in the classroom. For the listening teaching model based on Construction theory and network multimedia technology used in the experiment, many students are still not suitable for this teaching method. Although in terms of students, in such a listening learning atmosphere, they have low anxiety and are more suitable for listening, but they are very different from their consistent understanding of listening and English classes. At the same time, although the whole experiment spans a school year, due to various preparation time and limitations of listening time, the actual implementation of the experimental phase is still too short and has not helped the students to integrate well into the learning mode. Some students still feel that the best way to improve their listening skills is to do listening questions. This kind of test-taking method still has a large proportion in current students. Therefore, the author believes that the reform of listening and speaking teaching is not a one-off event and it is necessary to make long-term plans. Teachers should change the attitude of students' foreign language learning from the perspective of concept and let them recognize the essence of foreign language learning: language is a system and learners are the main body of foreign language learning. Learning is a construction process in which the original schema knowledge and new knowledge interact. Therefore, teachers should encourage students to actively participate in foreign languages, so that they pay more attention to the learning process and effects.

\subsection{The limitations of various objective hardware also greatly affected the effectiveness of this experiment.}

According to the requirements of student management in our school, freshmen cannot be equipped with computers. This kind of requirement is more to consider that the freshmen's 
self-control ability is relatively weak and the time in university life is relatively loose, which makes some unconscious students easy to indulge in the network. However, because the current teaching materials are accompanied by CD-ROM materials, students have difficulty in self-study outside the classroom. Moreover, in this experiment, network multimedia is a very important link and it is an important way for students to extend classroom listening and speaking to extracurricular activities. Therefore, the above management requirements also make this teaching consistency greatly compromised. The author believes that in order to balance the needs of student management and teaching, it is possible to improve the utilization rate of the extracurricular activities in the listening laboratory and the computer laboratory as much as possible and become an important way for students to learn independently.

\subsection{Listening and speaking teaching based on constructivist theory and network multimedia technology pays more attention to the learning process}

Pay attention to the active construction of knowledge in the learning process. The design of classroom activities is more of an interactive teaching mode, which increases the information interaction between teachers, students and students. However, there are relatively few test-type listening exercises. This is also a significant reason why the improvement in the performance of the experimental class is not very obvious compared to the control class. But the author believes that this is also largely due to experimental time. If you can make the experiment span longer, let students truly become the main body of the listening and speaking process and actively encourage their independent learning outside the classroom, in the long run, it will definitely improve the students' listening level. Moreover, that kind of improvement will be a benign cycle. As students improve their level of self-learning, the improvement of their interest in learning will give them higher goals, which in turn will lead them to seek better learning methods and more difficult learning materials.

\section{Conclusion}

In summary, the five teaching links are closely related. It is aimed at the teaching characteristics of college English and the exploration of students' cognitive rules. It is a new learning style and cognitive processing strategy for students and it is the formation of students' knowledge and understanding. We hope that by developing students' self-control skills, they will become independent learners, complete and deepen the meaning construction of knowledge and achieve the ultimate goal of teaching goals.

\section{References}

[1] Hsing-chin Lee. Social media and student learning behavior: Plugging into mainstream music offers dynamic ways to learn English [J]. Computers in Human Behavior, 2014,36.

[2] Jinfen Xu,Banban Li,Andy Curtis. Validating an English language teaching reflection inventory in a Chinese EFL context [J]. System, 2015,49.

[3] Ru-Chu Shih,Chunyi Lee,Tsai-Feng Cheng. Effects of English Spelling Learning Experience through a Mobile LINE APP for College Students [J]. Procedia - Social and Behavioral Sciences, 2015,174.

[4] Jie Yang,Chee Keong Yuen. College English Teaching Methodology and Language Planning: A Pilot Study in Hefei, China [J]. Procedia - Social and Behavioral Sciences,2014,118.

[5] Alla Zareva. Multi-word verbs in student academic presentations [J]. Journal of English for Academic Purposes, 2016,23. 